\title{
Industry Best Practice Risk based design for LPG Facility: Gap in Bangladesh practice
}

\author{
Dr. Kamrul Islam ${ }^{1}$ and Sharmin Sultana ${ }^{2}$ \\ ${ }^{1}$ DynSoL AS, Forusparken 2, 4031 Stavanger, Norway \\ ${ }^{2}$ Faculty of Engineering, Norwegian University of Science and Technology, Norway
}

\begin{abstract}
Bangladesh safety regulations and practice is at nascent stage. Safety distance regulation for LPG installation does not match with prescriptive standard API 2510 or other international standards. No detail technical basis is available publicly for such decision making by authority. The present study focuses on risk based design best practice in industries and gap in Bangladesh safety regulations. World LPG industry faces major accidents with fatalities and huge damages. Setting up bigger safety distance with conventional firefighting equipment is not the only mitigation measures to solve complex safety issues of LPG facilities. These two parameters do not ensure whether facility risk is tolerable and ALARP. Apart from this, safety distance and protection system design varies with facility layout, wind flows, systems reliability and site ambient conditions. For accident cases, hazards consequence modeling is carried out to calculate safety distances. Industry best practice is to apply risk based design that quantify complex risk level of a facility, propose mitigation measures and thereby risk acceptance criteria in the early phase of the project for authority approval. Many countries follow such detail regulation. Regulations of API, ISO, HSE UK and NORSOK, petroleum authority Norway have been utilized as basic standards in this paper. Gap in Bangladesh safety regulations are identified. This need to be further assessed based on industry best practice risk based design standards and practices. Without appropriate regulation, Bangladesh LPG industry and society remains in enormous intolerable personnel, environmental and economic risk.
\end{abstract}

Keywords: Risk based design, risk assessment, safety distance, ALARP

\section{Introduction}

LPG storage facility risk is very high and was evident from different LPG accident histories including Mexico accident. In 1984, Mexico city was affected by deadly accident, consequence of which was Blast waves destroyed houses, added cylinder gas to the fire, cylinder fragments and even 30 tons of cylinder scattered over few to $1200 \mathrm{~m}$. The facility had 4 LPG spherical storage of $1600 \mathrm{m3}$, two 2400 m3, 48 cylindrical storages of diff sizes. Should the safety distance then be $1.2 \mathrm{~km}$ ?[1]. Complex factors leading to major accidents, deflagration or detonation, serious consequences and relevant safety measures are of great interest to researchers and industrial companies. The present study focuses on risk based design to identify hazards and mitigate risk. Gap in Bangladesh regulation is identified with respect to industry standards and best practices.

Risk based design identifies the varied conditions during a potential accident and mitigate risk by using control measures. Control measures are systematically assessed in the design phases of a specific facility by using different studies like HAZID, HAZOP, QRA, LOPA, SRS etc. Results can also be used as a reference for emergency response planning. With the aid of consequence simulation and QRA (quantitative risk assessment) technique, the plant site safety can be effectively improved by means of implementing the preliminary hazard assessment and suitable preventive control strategies.

\section{Learning from previous accidents}

LPG accidents in Mexico shows materials scattered at maximum distance $1200 \mathrm{~m}$. sphere fragment landed at a distance of $700 \mathrm{~m}$. High pressure gas safety institute of Japan presented huge LPG accident casualties in Japan [8] since 1968. [11] presented different LPG accidents and evaluated causes of accident.

At least five to six cases of fire incidents are reported in the city every month, in which leakage or defects in LPG installations has been found to be the trigger of the blaze [10].Cylinder explosion deaths are 91 in 96 accidents in India [9].

\section{Requirement in Standards}

NFPA 58 provides many prescriptive guidelines for designing, commissioning, operating, and maintaining safety systems. NFPA does not

\footnotetext{
* Corresponding author: Dr.-Ing. Kamrul Islam, TD R\&D, DynSoL AS Norway,

Email ki@dynsolonline.com
} 
prescribe specific hazard evaluation techniques to accomplish site specific risk based safety objectives. API 2510. API 2510 5.1.1.3 instruct to safety analysis and dispersion modelling to limit the exposure risk to adjacent facilities.

Section 5.1.2 standardised safety distance for LPG facilities as follows

Table 1: Minimum horizontal distance between shell of pressurized LPG tank and line of adjoining property that may be developed

\begin{tabular}{cc}
\hline $\begin{array}{c}\text { Water capacity of each } \\
\text { tank (gallons) }\end{array}$ & $\begin{array}{c}\text { Minimum distance } \\
(\mathrm{ft})\end{array}$ \\
\hline $2000-30000$ & 50 \\
$30001-70000$ & 75 \\
$70001-90000$ & 100 \\
$90001-120000$ & 125 \\
120001 or greater & 200 \\
\hline
\end{tabular}

Excerpt from API 2510 Section 10

"Fire protection provision shall be based on a safety analysis of local condition, exposure from or to other sites, availability of a water supply, and effectiveness of fire brigades and fire departments. The analysis shall include possible but realistic accident scenarios that may occur, including scenarios of vapor release, ignition and fire. For additional information, background and guidance, see API publ 2510A."

"A safety analysis shall be used to determine the need for fire and hydrocarbon detection systems. Where provided, fire and hydrocarbon detection systems shall be arranged to sound their alarms whenever fire or hydrocarbons are present. It is permitted to use detection systems to automatically activate isolation or fire protection systems in remote or unattended facilities."

World LPG regulations included risk assessment and ALARP requirement.

Carry out risk assessment is required by law in many countries. Risk assessment not only covers a systematic site-specific risk management for all potential hazards for facility life-cycle.

Relevant standards

- ISO 31000 - Risk Management

- ISO 31010 - Risk Management - Risk Assessment Techniques

- NORSOK Z-013 - Risk and emergency preparedness assessment

- ISO 13708 - control and mitigation of fire and explosion

- ISO 15544 - Emergency response

- ISO 17776 - Assessment of hazardous situations

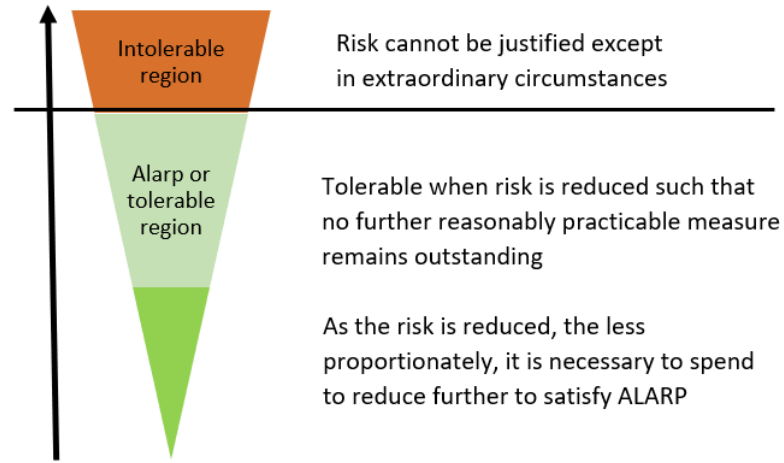

Fig. 1: ALARP principle according to Norwegian legislation (from NORSOK Z 013)

Example UK regulations

Safety case regulation:

- The duty holder is required to demonstrate through the safety case that the risk level for personnel on the installation is "as low as reasonably practicable (ALARP). This can only be effectively done through the use of QRA.

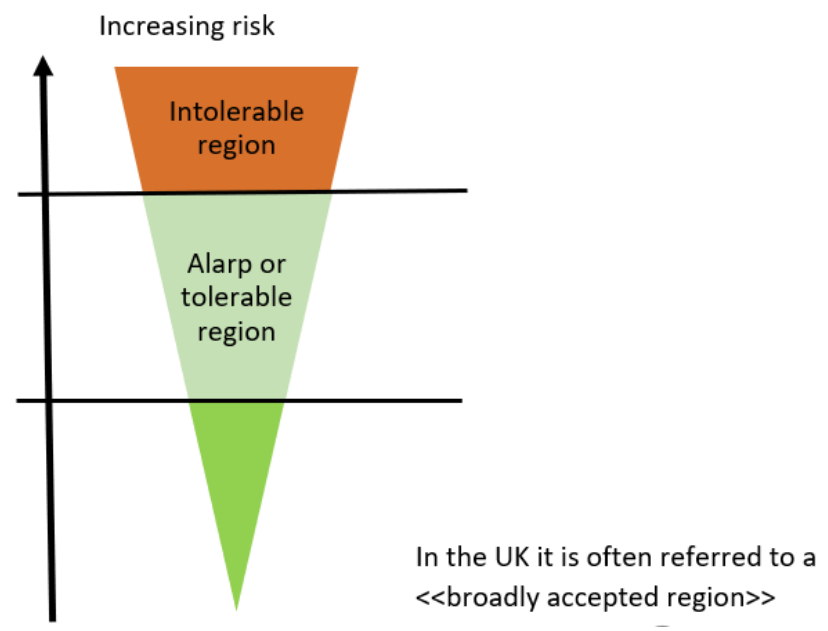

Fig. 2: Examples: UK regulations

\section{Risk Based design Methodology}

The Safety Strategy should be developed in accordance with recognized principles for HSE management systems, e.g. guidelines provided by industry standards. The Safety Strategy is the outcome of a systematic identification and evaluation of the hazards and effects which may arise on the actual facility and will define the need for, and role of, the risk reducing measures and safety systems.

The Safety Strategy shall outline the design principles for layout, arrangement and the selection of which safety barriers and systems to go into the design, ensuring a consistent and robust design that 


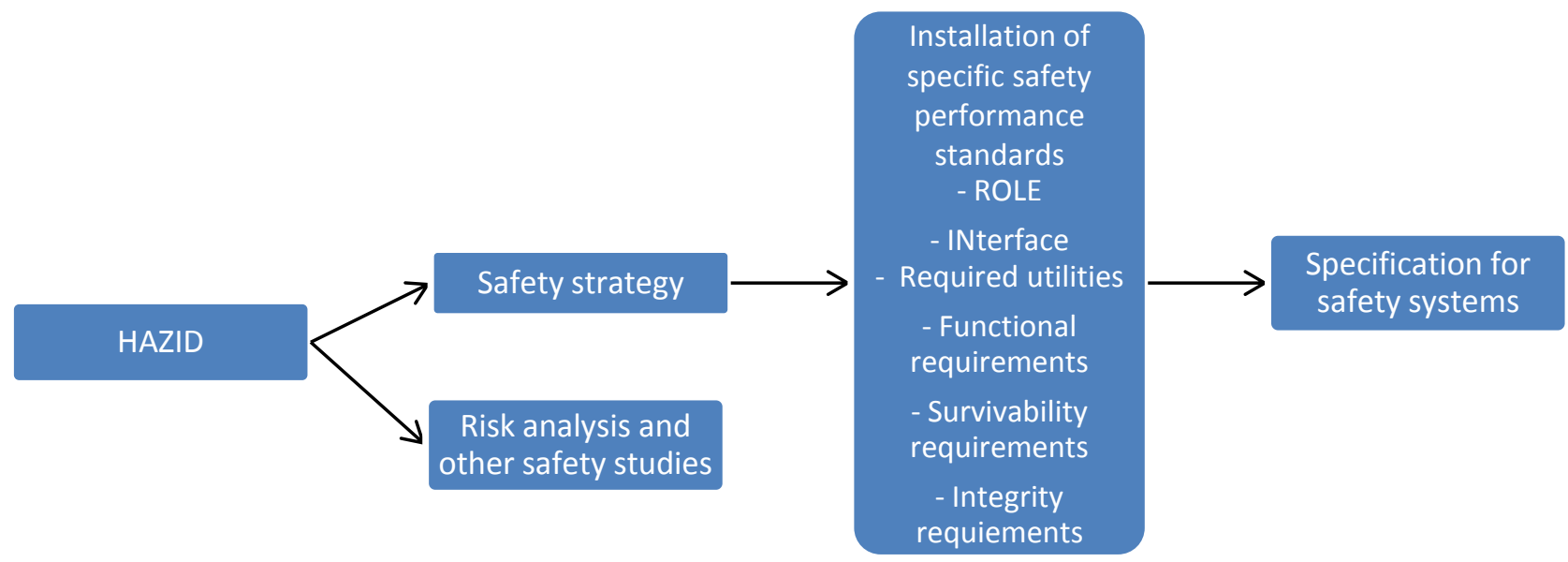

Fig. 3: Risk based Design Methodology

will be the basis for a safe operation of the facility. Operational aspects shall be addressed in the Safety Strategy, which then should serve as an input to the development of the operational procedures. The Safety Strategy shall reflect facility specific conditions, e.g. environment and climate, competence of staff, cultural elements, infrastructure such as transport, telecommunications and health care, availability of supplies of water and electricity, etc. Emergency preparedness aspects shall also be covered by the Safety Strategy. The flow chart [3] shows the methodology briefly.

\section{Gap in Bangladesh regulations}

Bangladesh authority defined safety distance of 120 $\mathrm{m}$ for spherical LPG tank which does not match API or other prescribed standards. Calculations in the following section shows that safety distance varies based on physical consequence. Without a safety strategy and understanding actual hazards and risk by conducting risk assessment, tolerable risk/ ALARP is not ensured. So local regulation does not comply with API and other risk related standards in section 4. Therefore, such shortcut does not mitigate actual risk on site. The requirement is missing many key steps of risk based design procedure and such facility risk has intolerable level to personnel and society.

\section{Consequence modelling}

In the last 30 years, comprehensive computational fluid dynamics. CFD, models for consequence modelling are developed and give realistic results. However, empirical models [4] are used for calculation of the safety distance for this study for quick demonstration. Worst case scenario is modelled. Hazards mitigation contribution in terms of risk mitigation factor for firewater or another safety systems are excluded. Empirical results are normally conservative than CFD modelling results due to CFD calculation's geometric effect and more precise mass and energy balance simulation. Fireball from three different LPG tank containment is considered. Heat radiation for these three cases were calculated. LPG properties used in the calculation are shown below Table 2 .

Table 2: LPG properties

\begin{tabular}{lcc}
\hline Properties & Unit & $\begin{array}{c}\text { LPG } \\
(30 \% \text { Propane, } \\
70 \% \text { Butane })\end{array}$ \\
\hline MW & $\mathrm{g} / \mathrm{mol}$ & 53.914 \\
Boiling point & ${ }^{\circ} \mathrm{C}$ & -13.3 \\
Liquid Density & $\mathrm{kg} / \mathrm{m}^{3}$ & 562.70 \\
Gas Density & $\mathrm{kg} / \mathrm{m}^{3}$ & 2.32 \\
Heat Capacity & $\mathrm{J} / \mathrm{mol}^{3} \mathrm{k}$ & 91.02 \\
Heat of Vaporization & $\mathrm{Kj} / \mathrm{mol}$ & 21.49 \\
Heat of Combustion & $\mathrm{Kj} / \mathrm{mol}$ & 2679.9 \\
\hline
\end{tabular}

Fireball consequence is modelled. Other consequences like pool, jet fire, explosion and tank fragments travel distance have not been estimated in this study for time constraint however this should be future study topic to identify consequences that may results in more than few hundred meters hazards distance.

\section{Results and discussions}

Results of the fireball calculation presented in Table 3. For Fireball Consequences initiated from tank failure, maximum Safety distance is estimated about $975 \mathrm{~m}$ from tank. Table 1 (API) shows maximum safety distance for tank is $61 \mathrm{~m}$. Distance observed from historical accidents are very high. This could be due to different ambient and wind conditions and domino effects. Safety distance requirement could be even higher based on consequence scenarios. But defining safety distance several hundred meters high is not the way to mitigate risk for proper land 
use planning. Overall risk analysis and inherently safer design, system reliability must be designed to mitigate risk to ALARP. Other consequence (i.e pool fire, explosion) modeling also needs to be conducted to verify the safety distance. Tank fragments due to explosion must be assessed in the future study.

Table 3: Fireball consequence distance

\begin{tabular}{ccc}
\hline $\begin{array}{c}\text { Cases- Tank } \\
\text { Inventory in MT }\end{array}$ & $\begin{array}{c}\text { Radiation 12.5 } \\
\mathrm{kW} / \mathrm{m}^{2} \text { at } \\
\text { distance in } \mathrm{m}\end{array}$ & $\begin{array}{c}\text { Radiation 4.7 } \\
\mathrm{kW} / \mathrm{m}^{2} \text { at } \\
\text { distance in } \mathrm{m}\end{array}$ \\
\hline 2000 & 655 & 975 \\
1000 & 520 & 775 \\
500 & 415 & 625 \\
\hline
\end{tabular}

It is evident that safety distance mentioned in API and other standards are based on overall risk analysis. Therefore, a minimum safety distance is set together with other risk mitigation measures. Bangladesh regulation has no risk assessment requirement that makes it noncompliant with standards and industry best practices. Bangladesh safety distance need to be assesses based on scientific methods and further work is needed in this regard.

\section{Conclusion}

This study has presented industry best practice risk based design methodology (safety/risk assessment) and identified gap in Bangladesh current practice. No risk assessment is being done currently in LPG projects for authority approval. In addition, special focus is given on safety distance defined in legislative requirement. It is evident that safety distance requirement is higher than API and much below the results obtained in this study. Future work shall include risk assessment which means all types of consequence analysis and mitigation measures. It is primarily revealed from this study that LPG tank safety distance requirement in Bangladesh has to be assessed based on scientific available methods and industry best practice. Since Safety distance and fire equipment do not ensure risk of the facility in a tolerable level, risk based design approach need to be part of legislative requirement to mitigate risk of LPG facility to a tolerable level (ALARP).

\section{References}

1. Journal of Hazardous Materils, 20 (1988) 85107 Elsevier Science Publishers BV, Amsterdam

2. S. Chand. Kiran A, Professional Safety, September 2015 www.asse.org , Quantified Risk Assessment, Understanding the Hazards of LPG Filling Stations

3. Risk assessment steps in Norwegian Petroluem Industries (ie Statoil)

4. Andreassen M 2008, Handbook for fire calculations and fire risk assessment in the process industry.

5. Bangladesh Petroleum autority regulation 2017 January

6. HSE UK, 2006, Guideline on risk assessment and safety statement

7. https://www.khk.or.jp/english/dl/annual_report_ lpg_2013.pdf

8. https://timesofindia.indiatimes.com/city/chenna i/LPG-cylinder-is-a-ticking-bomb-instate/articleshow/14683460.cms

9. https://www.telegraphindia.com/1120405/jsp/n ortheast/story_15335760.jsp

10. Joaquim Casal, Evaluation of effects and consequences of major accidents in Industrial Plants, Industrial Safety Series volume 8, Elsevier Publication 